DOI: 10.22616/REEP.2020.011

\title{
Case Study: Transversal Skills in Secondary School Mathematics
}

\author{
Gatis Lāma Mg.math. \\ University of Latvia, Latvia \\ gatis.lama@gmail.com
}

\begin{abstract}
Today's labor market requires specialists with advanced transversal skills who are able to adapt and develop themselves according to the needs of the workplace. Unlike technical skills, transversal skills are more sustainable than knowledge, because they are less influenced by technology development. Technology advancement requires the development of transversal skills not only at higher education but also in schools. The aim of the study is to assess pupils' transversal skills in secondary school. For this purpose, a classroom survey was conducted using pupils' self-assessment questionnaires as well as participant observation. The study was conducted at a secondary school in Riga during a lesson of calculus where the whole class of 26 pupils was participating in group work activities. This study deals with transversal skills such as collaboration, decision-making and self-discipline. The results show that there is a significant difference in development between studied transversal skills. The level of collaborative and self-discipline skills is significantly higher than the level of decision-making skills. The study also shows the positive role of setting criteria in the decision-making process.
\end{abstract}

Keywords: secondary education, transversal skills, collaboration, decision-making, self-discipline.

\section{Introduction}

Non-routinized and interactive tasks are increasingly identifying professions, thereby also increasing the importance of transversal skills (Direito, Pereira, de Oliveira Duarte, 2014) as key quality criteria for the employee. These processes have led to the need for a global movement that ensures that education goes beyond the acquisition of knowledge, literacy and computing skills, which has been the dominant goal of education in the economic discourse of official education since the nineteen sixties. This movement, also known as the $21^{\text {st }}$ century movement, is appropriate in an era in which we move away from an economic model based solely on production (UNESCO, 2015).

Although the importance of transversal skills for today's pupils or future professionals is well known, there is still a lot of discussion about which of these skills are most important. In addition, a number of related terms such as general skills, cross-curriculum skills, $21^{\text {st }}$ century skills and soft skills can be used both as synonyms and include a special meaning in certain contexts (Karapetjana et al., 2017) P21 (Partnership for 21 st..., 2019) theoretical framework of $21^{\text {st }}$ century skills, stresses that the acquisition of traditional subjects (mathematics, science, language, arts and social studies) should not be ignored, but recommends that broad and modern themes be identified and linked to acquisition of transversal skills.

In education, transversal skills allow students to see connection between the knowledge and skills of different school subjects in the pedagogical process. This is envisaged in the new project devoted to the development of the new teaching/learning content School 2030 (Skola 2030, 2016) which anticipates focusing on the following transversal skills in the curriculum: self-cognition and self-management; thinking and creativity; cooperation and participation; digital literacy (Andersone, Helmane, 2018).

Based on analysis of the $21^{\text {st }}$ century skill frameworks the National Research Council offered to categorize them in three broad categories (Pellegrino, Hilton, 2012):

\section{- The Cognitive Domain}

Includes cognitive processes and creativity.

Characteristic transversal skills: critical thinking, information literacy, reasoning and argumentation, and innovation.

\section{- The Intrapersonal Domain}

Includes intellectual openness, work ethic and conscientiousness, and positive core self-evaluation. Characteristic transversal skills: flexibility, initiative, appreciation for diversity, and metacognition

\section{- The Interpersonal Domain} Includes teamwork, collaboration and leadership. 
Characteristic transversal skills: communication, collaboration, responsibility, and conflict resolution.

However, E. Care and R. Luo (2016) categorize the transversal skill in six broad domains and characterize each domain with intrinsic transversal skills:

- critical and innovative thinking - creativity, entrepreneurship, resourcefulness, application skills, reflective thinking, reasoned decision-making;

- interpersonal skills - communication skills, organizational skills, teamwork, collaboration, sociability, collegiality, empathy, compassion;

- intrapersonal skills - self-discipline, ability to learn independently, flexibility and adaptability, self-awareness, perseverance, self-motivation, compassion, integrity, self-respect;

- global citizenship - awareness, tolerance, openness, responsibility, respect for diversity, ethical understanding, intercultural understanding, ability to resolve conflicts, democratic participation, conflict resolution, respect for the environment, national identity, sense of belonging;

- media and information literacy - ability to obtain and analyze information through ICT, ability to critically evaluate information and media content, ethical use of ICT;

- other (physical health, religious values) - appreciation of healthy lifestyle, respect for religious values.

The development of transversal skills requires a flexible learning environment that helps pupils to develop a range of skills simultaneously leaving room for basic skills (Wahlström, 2016). Development of transversal competences is stimulated through active training methods that are used in group work. Active training methods used in group work are best suited for developing transversal skills (Díaz Pareja et al., 2018). On the basis of a theoretical analysis of the $21^{\text {st }}$ century skills or transversal skills the following transversal skills were selected for further research: collaboration, decision-making and self-discipline.

\section{Collaboration skills}

For collaboration to take place, there is a need for motivation and space for its development. The organization of the process should ensure collaboration commitments and structure necessary to adopt, recognize and promote the collaboration process (Newell, Bain, 2018). K. van de Oudeweetering and J. Voogt (2017) defines collaboration skill as the ability to achieve a goal as a team, as well as the ability to complement and support each other. Collaboration is characterized by joint objectives and capacity of participants to operate at a similar level of development (Oliveira, Tinoca, Pereira, 2011). The ability to cooperate, including the ability to make joint team decisions, is seen as an important skill for the individual in order to be prepared for the challenges of the $21^{\text {st }}$ century. This type of collaborative skills is considered to be an important learning outcome (Khlaisang, Mingsiritham, 2016).

Collaboration skills can be developed in the traditional learning environment, using different methods. One of the most appropriate methods to develop collaboration skills is group work. Collaboration through intensive interaction and communication (Khlaisang, Mingsiritham, 2016; Stramkale, 2018) as well as the ability to organize work, and to take responsibility for the duties to be carried out, is an important element of group work. C. Newell and A. Bain (2018) considers that a successful collaboration is based on mutual relations.

Mutual respect helps common communication as well as the assessment and acceptance of the diversity of views and solutions proposed, as respect for one another helps partners assess their role in achieving the common objectives. However, it should be noted that the social, cultural, political and philosophical background of each group member also plays an important role. The members of the group should be flexible, able to compromise in order to achieve a common objective and to assume mutual responsibility for a common task. The personal contribution of each member should be valued by each member of the group (Gkemisi et al., 2016). However, collaboration should not only be used to achieve individual learning objectives. Important collaborative tasks should be to exchange new ideas, sharing thoughts and information (Khlaisang, Mingsiritham, 2016).

Although collaboration skills are best developed through long-term projects, particularly projects that are fully structured by students themselves (Moore, 2016), day-to-day learning environments also provides the opportunity to cooperate with each other with a greater variety of pupils and challenges. 
Group work as a learning method is effective in improving collaboration skills, learning in small groups is particularly important. However, in addition to the experience of working in well-resource groups, some members do not change attitudes to group work and they continue to prefer individual work (Bernier, Stenstrom, 2016).

\section{Decision-making}

Making a decision is a choice between multiple options and is considered a cognitive process. While decision-making skills can be developed at different ages, independent decision-making skills can be developed during adolescence (Truong, Hallinger, Sanga, 2017). Decision-making is related to the way learner responds to specific incentives (Aarskog, Barker, Borgen, 2019). Decision-making can also be conceptualized as a set of habits (Aarskog, Barker, Borgen, 2019) which is often an essential factor in the selection process. When looking at decision-making from such a perspective knowledge and previous experience is most important decision-making characteristics.

Decision-making is complex and is not possible without well-developed problem solving and critical thinking skills. A key prerequisite for decision-making skills is the ability to judge the causes, consequences, benefits and disadvantages of the problem, and the ability to seek different alternatives to the problem (Nicolaou et al., 2009). T.D. Truong, P. Hallinger and K. Sanga (2017) believes that the factors most affecting decision-making are an individual's role, skills, knowledge, experience and character qualities. The decision-making situation itself often consists of a variety of options that can be identified before decisions are taken (Gresch, Hasselhorn, Bögeholz, 2013). The variety of decisionmaking styles - from habit-based to complex problem-solving outcome - makes this skill versatile and difficult to measure. V. Duran, H. Mertol (2019) highlights key decision-making styles such as: rational, intuitive, spontaneous, and decision-making and regulating processes: dependent and evasive.

In this research rational decision-making style is emphasized, which is characterized by information searching and evaluation of logical alternatives. The ability to make a decision is particularly important and complex in non-routine and unpredictable situations.

\section{Self-discipline}

The concept of self-discipline is closely associated with self-control. The synthesis of self-discipline and self-control is a prerequisite for the creation of a harmonized learning environment (Brundrett, Lungka, 2019). Self-discipline and self-control help reduce stress in the classroom for both pupils and teachers. Self-discipline is perceived as socially and morally responsible behavior motivated mainly by internal factors, not just external positive inducements or fear of punishment (Brundrett, Lungka, 2019).

An individual with high levels of self-discipline is able to effectively address impulse-driven conflicts and focus on long-term objectives that require greater effort and resilience (Flowers et al., 2011). Selfdiscipline is an essential skill for successful collaboration, particularly in groups. Students with high self-discipline are able to control impulse-driven answers (Hagger, Hamilton, 2018) and focus on task. Pupils with well-developed self-discipline are characterized by reliability, hard-working, the ability to complete the task (Jung, Zhou, Lee, 2017). The development of pupils' self-discipline should be a primary objective in the pupils' development process. Self-discipline also contributes to thinking discipline (Brundrett, Lungka, 2019) and the ability to implement a previously designed plan. Low selfdiscipline not only limits the individual, but also creates complex behavioral problems for surrounding pupils at class level (Brundrett, Lungka, 2019). Self-discipline is one of the most desirable qualities that pupils can develop regardless of their age as it positively affects the level of learning and personal growth (Hagger, Hamilton, 2018).

The aim of the study is to assess pupils' transversal skills in secondary school.

\section{Methodology}

As previously stated, group work is well suited for the development of transversal skills, therefore, the study took place in a calculus lesson where pupils were engaged in group work activities. The level of pupils' transversal skills was determined using self-assessment questionnaires and conducting participant observation. The study took place in Riga X Secondary School and involved 26 secondary school pupils. 
The task given to pupils divided in equal the groups of four people, chosen by the pupils themselves, was to create a poster, summarizing function limits. The group work lasted 80 minutes and consisted of three phases.

- Introduction phase during which participants were presented with the tasks to be performed and evaluation criteria. It was noted that the results achieved were going to be evaluated as well as the process and transversal skills - decision-making, collaboration and self-discipline.

- Operational phase. During the operational phase the pupils performed a joint task - creating a poster, as well as jointly formulated their views on the selection of work content and selection criteria.

- Closing phase. In the closing phase, pupils commented on decision-making skills, collaboration and self-discipline by filling out a self-assessment questionnaire, assessing seven statements using Likert scale.

The whole process was also assessed by a researcher with observation method.

\section{Results and Discussion}

As part of group work, collaboration skills were measured with three statements. The statements examined three dimensions of collaboration skills:

- organization of a work characterized by the ability to jointly agree on the division of the task;

- final result, perceived as a result of joint group collaboration;

- contribution of each member of the group.

The results show a significant difference between these dimensions, $88 \%$ of respondents strongly agree and $12 \%$ agree that ideas of other members of the group were helpful in carrying out the task (Figure 1). $73 \%$ of respondents strongly agree and $27 \%$ agree that the group succeeded in quickly distributing job tasks. The results indicate that pupils believe that the process of the work organization and the process of generating ideas was successful. However, only $42 \%$ of respondents strongly agree and $58 \%$ of respondents agree with the statement that they are "fully satisfied with the created poster". It shows that there was difficulties with organization and design processes.

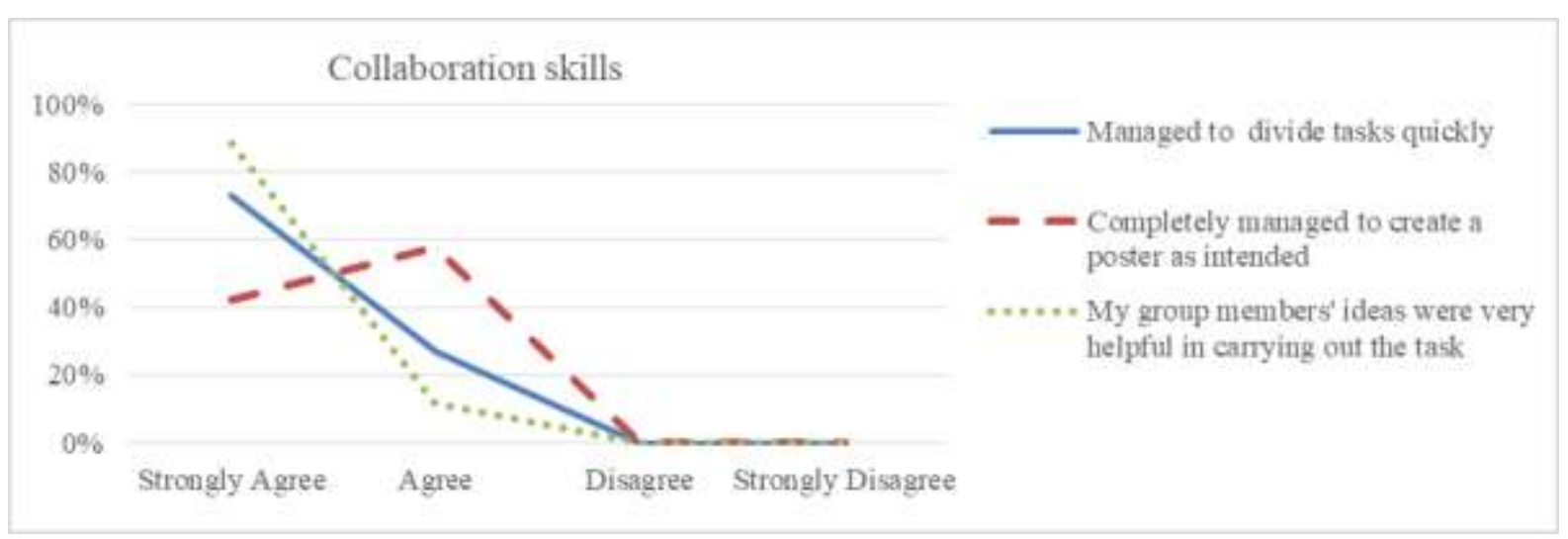

Figure 1. Collaboration skills.

The different results regarding these statements may be explained by difficulties in the decision-making process, which led to a lack of time to complete the task, but, more importantly, were influenced by the organization of the work. It was observed that all groups approached the task with a conventional group work strategy: three of the members of the group were involved in generating ideas and planning content, but only one was occupied with the realization of these ideas in drawing up a poster. This choice of strategy led to a lack of time. Only two groups (8 participants) out of seven were able to react to the problem at hand and managed to change their strategy at in an attempt to adapt.

By dividing the responses to this statement "fully satisfied with the created poster" into two parts: groups who were able to change the strategy and those who continued to work the same way, showed a significant difference in results. In the groups that changed the strategy no one strongly agreed and $100 \%$ respondents agreed that they were fully successful in carrying out the task. In groups where students were unable to change their strategies, the results of this statement were higher: $58 \%$ of respondents strongly agreed and $42 \%$ agreed (Figure 2). An evaluation of the completed posters found 
that for both groups that changed their strategy, the outcomes more complete than the outcome of groups that did not change their work strategy. Consequently, the question of this discrepancy between the outcome and the views of the pupils remains open. This could be explained by the difference in the assessment capacity of these groups, but also by the fact that only pupils who were able to understand the inadequacy of their strategies were able to assess the outcome more objectively.

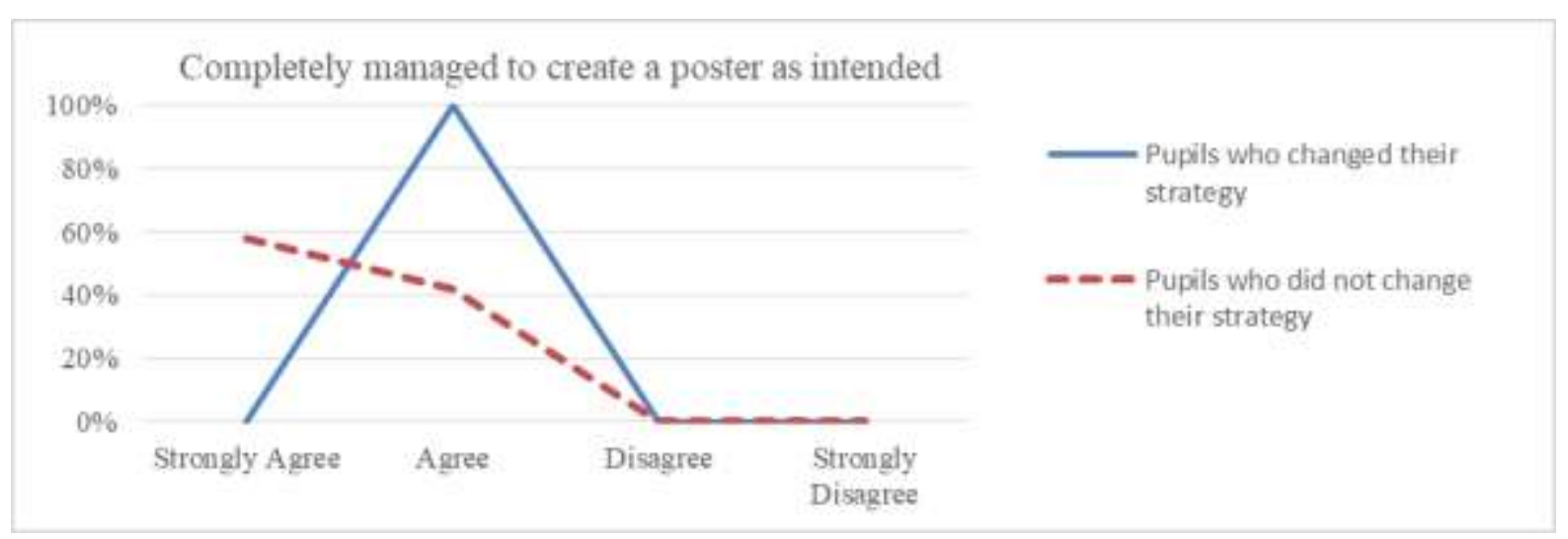

Figure 2. Statement "Completely managed to create a poster as intended".

One segment of the questionnaire was designed to address the decision-making process, which was measured with a question with the Likert scale and one open-ended question. There were no restrictions to the organization of decision-making process and pupils were allowed to divide the spheres of responsibility, make individual decisions, or discuss each decision as they pleased, it was observed that all groups chose to make all their decisions jointly. The majority (73\% of respondents) strongly agreed and the rest (27\% of respondents) agreed that they had decided quickly on the topics and examples to be included in the poster. The results indicate that decision-making skills, although generally rated as positive, are rated lower than collaboration skills and self-discipline.

In an open-ended question, participants had to formulate a single group view on the principles of how they selected the content for the poster. The answers to this question clearly indicated the criteria that were used as a basis for decision-making. The analysis of results revealed the following criteria that pupils used to determine the contents and design of their poster:

- topics that the participants are best acquainted with;

- content which is clear and easily explained;

- content that may be easily visualized;

- subjectively most relevant topics;

- topics that are applicable and usable in class.

At least one criterion for decision-making was raised in each of the groups. Dividing pupils according to the number of criteria set out in their group (one criterion or at least two criteria) shows that the number of criteria correlates positively with the results of the statement regarding decision-making. Of first group (pupils who had only one criterion) no one strongly agreed with the according statement and $100 \%$ chose the response "agree". While participants in the second group (at least two criteria) $39 \%$ of respondents strongly agreed and $61 \%$ agreed (Figure 3 ). It should be noted that the criterion of including content on the basis of the knowledge of the participants may be considered as a requirement and could be restrictive in decision-making, so that it shouldn't be fully regarded as a criterion.

Three statements were used to assess self-discipline, which included:

- concentration capacity to perform the task;

- the ability to avoid conflict situations,

- the ability to perform the tasks assigned. 


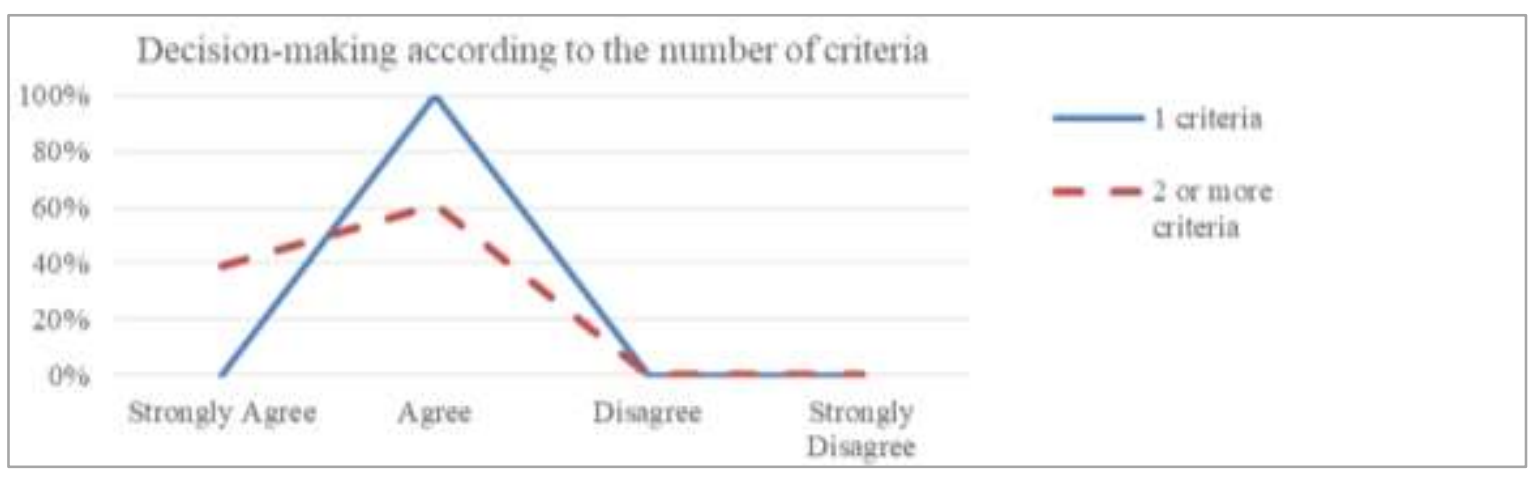

Figure 3. Decision-making according to the number of criteria.

The most of respondents (73\%) strongly agreed, $15 \%$ agreed and $12 \%$ did not agree with the statement "it was easy to focus on fulfilling the task". The majority (69\%) strongly agreed, $23 \%$ agreed and $8 \%$ did not agree that there were no significant conflicts in the decision-making. These were the only statements where answer "disagree" appeared, which may be due to a difficulties with the harmonization of different opinions. However, there were no major conflicts observed, which could indicate that they were small and pupils were capable to quickly resolve them (Figure 4).

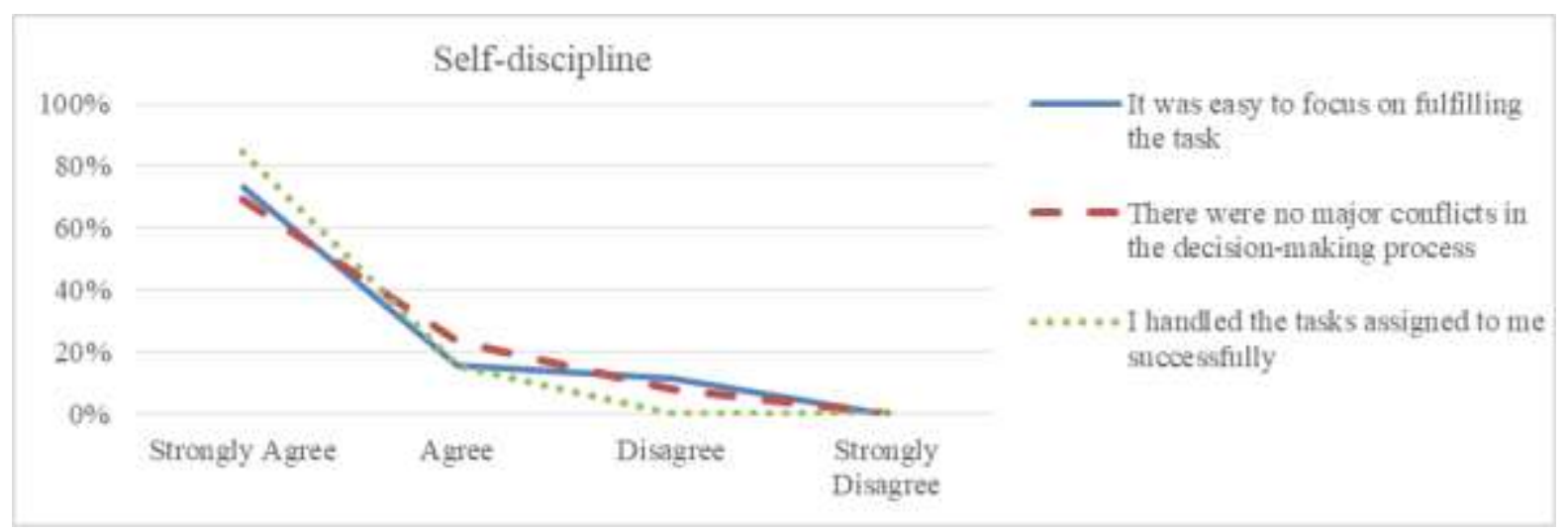

Figure 4. Self-discipline.

More than $4 / 5$ of respondents ( $85 \%$ ) strongly agreed and the other $15 \%$ agreed that they had done "a great job with the assigned tasks". The survey shows that the pupils' self-discipline has been the most evenly assessed. It was assumed that each transversal skill is characterized by the mean value of the each skills corresponding statements. It can be concluded that pupils have similarly valued collaboration and selfdiscipline, but the result for decision-making is significantly lower. This shows that decision-making seems more difficult for pupils (Figure 5).

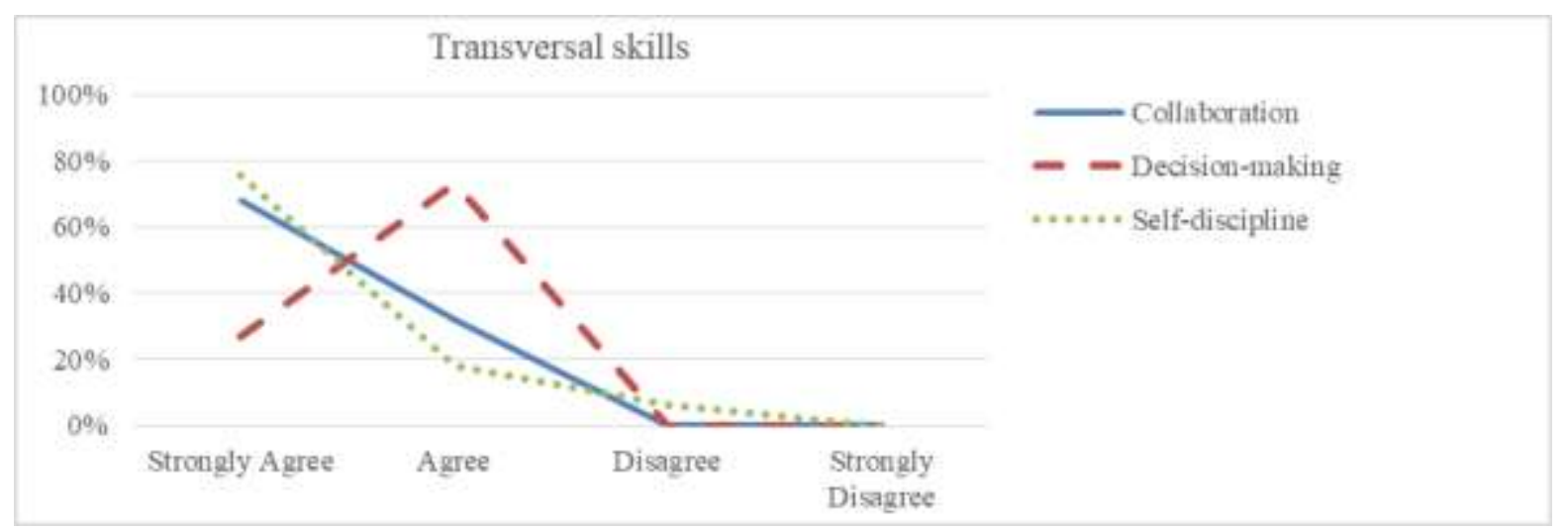

Figure 5. Transversal skills. 


\section{Conclusions}

The rapid development of technology changes not only the work environment, it also makes it necessary to change the learning process. It is essential to adjust the content and learning methods to promote the development of transversal skills. Research focused on three transversal skills: collaboration, decisionmaking and self-discipline. The results of the research show that the collaboration, decision-making skills studied in performing the task are well developed for the studied pupils.

Collaboration skills were measured by three components: 1) ability to organize tasks and processes among each other, 2) the final result as a joint group effort, 3) division of responsibilities. More than $2 / 3$ of participants assessed their ability to organize tasks and division of responsibilities with highest grade. Selfdiscipline was divided into three components: 1) ability to focus on the task, 2) self-control, 3) organization of individual tasks. Self-discipline was measured even higher than collaboration skills, as more than $3 / 4$ of respondents assessed all three components with highest grade. However, assessment of decision-making is significantly lower as only $1 / 4$ of all participants strongly agreed to the statements that measured this skill, leading to believe that this particular skill may be underdeveloped.

There have been a number of challenges and relations that need to be analyzed in the further studies.

Members of groups who were able to change the strategy in order to better execute the group's task underestimated their collaboration skills. This assessment is contrary to the researcher's observation and indicates that pupils are able to assess their skills according to their understanding and their comparison could be subjective.

The establishment of appropriate criteria greatly facilitates the decision-making process. Members whose group had at least two selection criteria have valued their decision-making skills significantly higher than members of groups with only one criterion. It was observed that the group work was performed better in those groups which members had better mutual relations.

The self-discipline of pupils in the group work process is very high. These results indicate that the given pupils have the capacity to implement self-guided learning processes.

\section{Bibliography}

1. Aarskog E., Barker D., Borgen J.S. (2019). What were you thinking? A methodological approach for exploring decision-making and learning in physical education. Sport, Education and Society, 24(8), 828-840. doi: 10.1080/13573322.2018.1491836

2. Andersone R., Helmane I. (2018). Interdisciplinary Education in Multicultural Environment. In V. Dislere (Ed.), The Proceedings of the International Scientific Conference Rural Environment. Education. Personality. (REEP), 11. Jelgava: Latvia University of Life Sciences and Technologies, 25-32. doi: 10.22616/REEP.2018.002

3. Bernier A., Stenstrom C. (2016). Moving from chance and "chemistry" to skills: Improving online student learning outcomes in small group collaboration. Education for Information, 32(1), 55-69. doi: 10.3233/EFI-150960

4. Brundrett M., Lungka P. (2019). The development of teachers' knowledge and behaviour in promoting selfdiscipline: a study of early years teachers in Thailand. International Journal of Primary, Elementary and Early Years Education, 47(4), 462-474. doi: 10.1080/03004279.2018.1498996

5. Care E., Luo R. (2016). Assessment of transversal competiencies: Policy and the practice in the AsiaPasific Region. Retrieved from https://unesdoc.unesco.org/ark:/48223/pf0000246590

6. Direito I., Pereira A., de Oliveira Duarte A.M. (2014). The development of skills in the ICT sector: Analysis of engineering students' perceptions about transversal skills. International Journal of Engineering Education, 30(6), 1556-1561. Retrieved from https://www.researchgate.net/publication/269335775_The_Development_of_Skills_in_the_ICT_Sect or_Analysis_of_Engineering_Students'_Perceptions_about_Transversal_Skills

7. Díaz Pareja E.M., Cámara Estrella Á.M., Muñoz Galiano I. M., Ortega-Tudela J.M. (2018). Group work: Prospective teachers' acquisition of transversal competences. Educational Studies, 44(1), 45-56. doi: 10.1080/03055698.2017.1331841

8. Duran V., Mertol H. (2019). Investigation of the Reasoning Styles of the Teacher Candidates in terms of Decision Making Styles, Learning Modalities and Gender (Süleyman Demirel University Education 
Faculty Case). European Journal of Contemporary Education. 8(3), 489-505. doi: 10.13187/ejced.2019.3.489

9. Flowers L.A., Moore J.L., Flowers L.O., Clarke M.J. (2011). Chapter 4 The Relationship Between Academic Self-Concept and Career Self-Efficacy Among African-American Males in STEM Disciplines at Two Historically Black Colleges and Universities: An Exploratory Study. In H.T. Frierson, W.F Tate, H.T. Friwrson (Eds.), Beyond Stock Stories and Folktales: African Americans' Paths to STEM Fields (Diversity in Higher Education, 11). Emerald Group Publishing Limited, Bingley, 73-83.

10. Gkemisi S., Paraskeva F., Alexiou A., Bouta H. (2016). Strengthening collaboration and communication skills in an online TPD program for 21st-century educators. International Journal of Learning Technology, 11(4), 340-363. doi: 10.1504/IJLT.2016.081710

11. Gresch H., Hasselhorn M., Bögeholz S. (2013). Training in Decision-making Strategies: An approach to enhance students' competence to deal with socio-scientific issues. International Journal of Science Education, 35(15), 2587-2607. doi: 10.1080/09500693.2011.617789

12. Hagger M.S., Hamilton K. (2018). Grit and self-discipline as predictors of effort and academic attainment. British Journal of Educational Psychology, 89(2), 324-342. doi: 10.1111/bjep.12241

13. Jung K.R., Zhou A.Q., Lee R.M. (2017). Self-efficacy, self-discipline and academic performance: Testing a context-specific mediation model. Learning and Individual Differences, 60, 33-39. doi: 10.1016/j.lindif.2017.10.004

14. Karapetjana I., Rozina G., Henkuzena I., Zaura E., Ribeiro S., Sarmento C. (2017). Transversal Skills in the World of Work: Applied Linguistics' Approach. Baltic Journal of English Language, Literature \& Culture, 7 , 87-105. Retrieved from https://www.lu.lv/fileadmin/user_upload/lu_portal/apgads/PDF/BJELLC-VII.pdf

15. Khlaisang J., Mingsiritham K. (2016). Engaging virtual learning environment system to enhance communication and collaboration skills among ASEAN higher education learners. International Journal of Emerging Technologies in Learning, 11(4), 103-113. doi: 10.3991/ijet.v11i04.5503

16. Moore C. (2016). The Future of Work: What Google Shows Us About the Present and Future of Online Collaboration. TechTrends, 60(3), 233-244. doi: 10.1007/s11528-016-0044-5

17. Newell C., Bain A. (2018). Team-Based Structures, Protocols and Problem-Solving Skills for Effective Collaboration. In Team-Based Collaboration in Higher Education Learning and Teaching. Singapore: Springer, 35-41. doi: 10.1007/978-981-13-1855-9_4

18. Nicolaou C.T., Korfiatis K., Evagorou M., Constantinou C. (2009). Development of decision-making skills and environmental concern through computer-based, scaffolded learning activities. Environmental Education Research, 15(1), 39-54. doi: 10.1080/13504620802567007

19. Oliveira I., Tinoca L., Pereira A. (2011). Online group work patterns: How to promote a successful collaboration. Computers and Education, 57(1), 1348-1357. doi: 10.1016/j.compedu.2011.01.017

20. Partnership for 21st Century Skills. (2019). Framework for 21st Century Learning Definitions. Retrieved from http://static.battelleforkids.org/documents/p21/P21_Framework_DefinitionsBFK.pdf

21. Pellegrino J.W., Hilton M.L. (Eds.). (2012). Education for Life and Work: Developing Transferable Knowledge and Skills in the 21st Century. Washington D.C.: The National Academies Press. Retrieved from https://hewlett.org/wp-content/uploads/2016/08/Education_for_Life_and_Work.pdf

22. Skola 2030. (2016). Par Projektu Atbalsts Mācību Pieejas Mainai [School 2030: About the Project Supporting a Change of Learning Approach]. Retrieved from https://www.skola2030.lv/lv/par-projektu (in Latvian)

23. Stramkale L. (2018). Student's Communication Activity in Small Group Learning. In V. Dislere (Ed.), The Proceedings of the International Scientific Conference Rural Environment. Education. Personality. (REEP), 11. Jelgava: Latvia University of Life Sciences and Technologies, 25-32. doi: 10.22616/REEP.2018.029

24. Truong T. D., Hallinger P., Sanga K. (2017). Confucian values and school leadership in Vietnam: Exploring the influence of culture on principal decision making. Educational Management Administration and Leadership, 45(1), 77-100. doi: 10.1177/1741143215607877

25. UNESCO. (2015). 2013 Asia-Pacific Education Research Institutes Network (ERI-Net) regional study on: transversal competencies in education policy and practice (Phase I): regional synthesis report. Retrieved from https://unesdoc.unesco.org/ark:/48223/pf0000231907

26. van de Oudeweetering K., Voogt J. (2017). Teachers' conceptualization and enactment of twenty-first century competences: exploring dimensions for new curricula. Curriculum Journal, 29(1), 116-133. doi: 10.1080/09585176.2017.1369136

27. Wahlström N. (2016). A third wave of European education policy: Transnational and national conceptions of knowledge in Swedish curricula. European Educational Research Journal, 15(3), 298-313. doi: 10.1177/1474904116643329 